DE DE GRUYTER

OPEN

DOI: 10.1515/aa-2015-0004

\title{
An Existential Psychoanalyst in the Literary Therapy Genre: The Representation of a Psychoanalytic Encounter in Irvin Yalom's The Schopenhauer Cure
}

\section{Huang, Yen-Chi}

Huang, Yen-Chi received her Master's degree in Literary Studies in 2011 and is currently a secondyear doctoral student of literature at Katholieke Universiteit Leuven, Belgium.

Her research interests include the literary therapy genre, psychoanalysis and literature.

\begin{abstract}
The aim of this paper is to describe the fictionalisation of psychoanalysis in the literary therapy genre written by psychotherapists. Being a psychotherapist, Irvin Yalom has written and published several literary therapy novels. The Schopenhauer Cure (2006) presents a psychoanalytic encounter with focus on the patient's interpersonal issues in a group therapy session and draws a parallel line between fictional patients and the philosopher Arthur Schopenhauer. The fictionalisation of patients' psychological symptoms and the way therapists examine themselves in the therapeutic milieu in The Schopenhauer Cure correspond to the fundamental concerns of isolation, meaninglessness, death and freedom in existential psychotherapy. I explore the literary representation of the psychotherapist and therapist-patient relationship and the therapeutic encounter in The Schopenhauer Cure in the context of how fictional narratives can be read as a form of highlighting the psychoanalytic encounter.
\end{abstract}

Based on an inquiry of the representation of a psychoanalyst's identity and the relationship between a psychoanalyst and a person-in-therapy, the theoretical discussion will focus on narrative function and the meaning of psychotherapy from the perspective of Yalom's existential psychotherapy. While the literary therapy genre has various narrative forms such as autobiographical narrative, memoirs, fictional, non-fictional writing etc, its content focuses on psychotherapy and psychoanalysis. Moreover, in order to explicate the meaning of psychoanalysis in contemporary the literary therapy genre, one could begin with an inquiry as to how literary therapy writing reveals the therapeutic encounter and mental healing process. What do the therapist and the person-in-therapy respectively experience in the therapeutic encounter? It is with such a proposition in mind that I propose an in-depth analysis of the representation of therapist, the therapist-patient relationship and therapeutic encounter in Irvin Yalom's The Schopenhauer Cure. By analysing the representation of therapeutic encounter in this fictional narrative, there will be a substantial understanding of the therapist-patient relationship, the experience of psychotherapy and the function of the psychoanalytic encounter in literary therapy genre. 


\section{Existential psychotherapy}

The goal of existential psychotherapy is to search for the meaning of being and its correlation to human dilemmas and existential situations. This corresponds to the fundamental concerns in existential psychotherapy: isolation, meaninglessness, death and freedom. All this may alone be enough to explain why a close reading will be given to the aforesaid existential concerns, the representation of the person-in-therapy's psychological symptoms and the ways in which therapists examine themselves as well as analyse the person-in-therapy in the therapeutic milieu in The Schopenhauer Cure. Existential psychotherapy includes various schools of psychotherapy with different conceptual and theoretical systems. I focus on the concise description of the fundamental principles of existential psychotherapy from historical and philosophical perspectives. To begin with, other than the "first force" of the Freudian school of psychoanalysis, from a psychological perspective, Erich Fromm, Abraham Maslow, Carl Rogers and Rollo May represent the rising of the humanistic psychology which emphasises the theme of human existence from a cultural and social perspective. The examples include psychological issues of will, meaning, self-actualisation, individuality and creativity (May, 1994). This theoretical cohesion provides the basis for the development of existential psychotherapy. One may assert that the common goal of psychotherapy is to decipher the mystery of human consciousness, to ease the pain and suffering of the human spirit via various means. For Freud, it was about soothing the conflicting forces or drives at the individual conscious and unconscious level. Comparatively speaking, existential psychotherapy starts its inquiry with the question of "being" from the perspective that the individual's basic conflicts come from "being." In the philosophical tradition of existentialism, there are many distinct philosophies concerned with the issue of being. Socrates, Pascal, Kierkegaard, Nietzsche, Husserl, Heidegger, Sartre and Merleau-Ponty as well as Buber and Tillich are in this long list of the western philosophical tradition of existentialism. To further elaborate, existential philosophy pays special attention to the existential dilemma encountered by human beings. What is more, the depth of existential philosophy is based on its confrontation of the fundamental and everyday situation of beingin-the-world. Whether existentialists who question the meaning of being or phenomenologists who take the phenomenological method as a means to approach the existence of being, they are the antecedents providing the philosophical background of existential psychotherapy. Such a philosophical tendency and approach are also what makes existential psychotherapy stand out from other contemporary psychotherapeutic methods. ${ }^{\mathrm{i}}$ Although some argue that existential psychotherapy is not a "health service” or health treatment (Szasz, 2005, p. 128), it is nevertheless well-recognised that the philosophical term "existential” has settled the tone of existential psychotherapy.

Also influenced by Rollo May and other antecedents of humanistic psychotherapy, Irvin Yalom, in his critically acclaimed Existential Psychotherapy (1980) proposes four existential concerns that are deeply rooted in the existence of human beings. They are respectively death, freedom, isolation and meaninglessness (Yalom, 1980, p. 8). How each of them is interwoven in one's life has become the central issue and ultimate concern of existential psychotherapy. Yalom further explains his concept of existential psychodynamics: "The existential position emphasises a different kind of basic conflict: neither a conflict with suppressed instinctual strivings nor one with internalized significant adults, but instead a conflict that flows from the 
individual's confrontation with the givens of existence" (Yalom, 1980, p. 8, italics in original). In other words, it is the givens of existence as well as the four ultimate concerns of death, freedom, isolation and meaninglessness that formulate each individual's own confrontation with life.

Moreover, such inevitable confrontation is also the origin of existential dynamic conflicts. These four fundamental concerns emphasise the essential nature and existential predicaments of human beings. Firstly, considering death as the fundamental origin of repressed fear and the primary source of anxiety, Yalom suggests that death anxiety prevails the structure of consciousness and existence (Yalom, 1980, p. 188). Human beings are afraid of the inevitable confrontation with death yet, meanwhile, they also try to find the means to defeat such death anxiety. ${ }^{\text {ii }}$ Yalom further develops the concept of the boundary situation as "an event, an urgent experience that propels one into a confrontation with one's existential situation in the world" (Yalom, 1980, p. 159). From the perspective of psychotherapy, Yalom proposes that the confrontation with the death and being in this boundary situation often initiate one's inner awareness, dramatic personal change and rearrangement of life's priority. As a result, the person-in-therapy might take this opportunity to transform a previously meaningless life structure into a state of authentic being.

Secondly, freedom means the realisation of one's full responsibility towards his or her state of absolute freedom. According to Yalom, "It is too much to beat, anxiety clamors for release, and, at both individual and social levels, we engage in a frenetic search to shield ourselves from freedom" (Yalom, 1980, p. 224), ${ }^{\text {iii }}$ there is no denying of the anxiety and consequences resulting from such ultimate personal freedom. The therapist's goal and project are to help the person-in-therapy to claim the freedom and assume his or her responsibility (Yalom, 1980, p. 222). Thus, the person-in-therapy's relationship with his or her freedom and responsibility becomes the source of conflicts. According to Yalom, "Therapy may then proceed to consider the possibility of choice, the myth of choicelessness, and the feelings evoked by a confrontation with freedom” (Yalom, 1980, p. 243), and this triangle relationship among freedom, responsibility and choice is often the source to cause the existential chaos of the person-in-therapy. To avoid confrontation with the three, especially responsibility, the person-in-therapy demonstrates typical symptoms of responsibility denial, or avoidance of autonomous behaviour (Yalom, 1980, p. 230). Nevertheless, such signs of anxiety also bring out the existential guilt in the person-in-therapy. Such existential guilt is embodied in the refusal of possibilities in life, strong self-denial, self-sacrifice and restriction: "There is general consensus among them that existential guilt is a positive constructive force, a guide calling oneself back to oneself " (Yalom, 1980, p. 280). The person-in-therapy's existential guilt is often the core towards psychotherapy and as a result, existential guilt becomes the guide to the person-in-therapy's potential and self-fulfilment.

Thirdly, from Yalom's perspective, existential isolation is a state of feeling spiritual separateness between oneself and others. "Existential isolation refers to an unbridgeable gulf between oneself and any other being. It refers, too, to isolation even more fundamental - a separation between the individual and the world" (Yalom, 1980, p. 355). In addition, existential isolation is stronger than interpersonal isolation: it is transcendental separateness. It should also be added that isolation confrontation is the crucial task in the therapeutic relationship. 
Fourthly, meaninglessness, as much as the goal and purpose to be pursued, the individual requires meaning to live by and to go on. The problem is, as Yalom describes, "How does a being who needs meaning find meaning in a universe that has no meaning?” (Yalom, 1980, p. 423). Yalom proposes several perspectives which can provide the individual with life purpose: altruism, self-dedication to a cause, creativity, a hedonistic solution, selfactualisation and self-transcendence (Yalom, 1980, p. 431). The most important addition to be made to what Yalom said about life meaning is that "Life meaning must be viewed in a developmental perspective: the types of life meaning change over an individual's life; other developmental tasks must develop meaning” (Yalom, 1980, p. 460). For Yalom, the central aim of existential psychotherapy is the understanding of existential predicaments of human beings and finding ways to accept and cope with inevitable existential situations and individual responsibility. Furthermore, existential psychotherapy encourages the individual to be aware of one's existential predicaments and hence to break into the everyday fixed patterns and act to change according to aforementioned awareness and personal will. During the existential psychotherapy process, despite the fact that the person-in-therapy may have to undergo crisis of meaning and as a result, to some degree, the person-in-therapy is granted the opportunity to explore him or herself throughout and finally opens new vistas within. One can conclude that Yalom's major contribution in existential psychotherapy is his formulation of four fundamental concerns as well as providing a psychodynamic model of existential psychotherapy.

\section{The Therapist-Patient Relationship and Therapeutic Encounter}

One of the most important factors in psychotherapy is the relationship between therapist and the person-in-therapy. One may start a theoretical inquiry by reflecting the following issues: what really happens during the psychotherapeutic encounter? What does the person-intherapy expect from the therapist and vice versa? What is the limitation of the relationship between therapist and the person-in-therapy? By pursuing these questions, one reaches the core of the therapeutic encounter: it is the relationship between the person-in-therapy and the therapist that is the central feature of the therapeutic process. Next, another important feature in the therapeutic encounter is transference. Transference involves both the person-in-therapy and the therapist. If one puts transference at the centre of the therapeutic action of psychotherapy, one would find out that a therapeutic relationship is full of projective/introjective identification and transference/counter-transference configurations. In order to fully explore the issue of transference, I approach it first from Freud's perspective on the therapist-patient relationship and then move to the existential therapist's counterperspective on the issue. In the first place, Freud applies the term "transference" to refer to the unique connection in the therapist-patient relationship. Freud argues that the person-intherapy's emotional projection or imagination towards the therapist constitutes the function of transference:

The patient is not satisfied with regarding the analyst in the light of reality as a helper and adviser who, moreover, is remunerated for the trouble he takes and who would himself be content with some such role as that of a guide on a difficult mountain climb. On the contrary, the patient sees in him the return, the reincarnation, of some important figure out of his childhood or past, and 
consequently transfers on to him feelings and reactions which undoubtedly applied to this prototype (Freud, 1940, p. 408).

What is immediately apparent in this extract is that the person-in-therapy's transference offers the therapist an opportunity to observe and to formulate an in-depth understanding of the person-in-therapy's life history and unconscious materials. As long as transference provides a non-hostile therapeutic milieu, one may conclude the positive side of transference because it strengthens the trust bond between the person-in-therapy and the therapist. Nevertheless, the danger of transference is that if the person-in-therapy transference becomes too strong, it may violate the balanced relationship between the person-in-therapy and the therapist. It is possible that the therapist may easily turn the therapeutic situation into a manipulative relationship by accessible intimate knowledge about the person-in-therapy. Such a view underlines the following remarks by Freud, "This transference is ambivalent: it comprises positive (affectionate) as well as negative (hostile) attitudes towards the analyst, who as a rule is put in the place of one or other of the patient's parents, his father or mother” (Freud, 1940, p. 408). Thus, apart from avoiding being too personally or emotionally involved with the person-in-therapy during the therapeutic session, the therapist should not deliberately take the accessible information of the analytical situation to his or her advantage. Furthermore, in order to remain objective and conduct professional psychoanalysis, Freud suggests that the therapist's symbolic function as an impersonal mirror reflecting the person-in-therapy's symptoms of neuroses and the therapist's professional detached presence is required during the therapeutic session (Davis, 2007). Nevertheless, compared to the intense therapist-patient relationship described in Freudian transference theory, to existential therapists, there is no effective therapeutic encounter without authentic engagement from both the therapist and the person-in-therapy. According to Yalom, the matter of the therapeutic relationship in the therapeutic encounter is "Therapeutic outcome/an accepting, trusting patient-therapist relationship is crucial to the process of change. As a result, the therapist's concern and unconditional regard, the patient's self love and self-regard gradually increase” (Yalom, 1980, p. 339). Compared to Freudian transference, here we can see different views on the issues of the therapeutic relationship in the therapeutic encounter from an existential psychotherapeutic perspective. The Freudian analyst withdraws from contact with the patient, whereas the existential analyst engages in the relationship in a positive, authentic manner. To put it the other way around, what is the focus of attention for an existential therapist when it comes to his or her relationship with the person-in-therapy in a therapeutic encounter? From the perspective of existential psychotherapy, what the therapist offers is not strict doctrine or merely disinterested professionalism, but a well-established recognition and acceptance of the person-in- therapy. Moreover, what the therapist needs is a pass to enter the person-intherapy's being-in-the world (Moustakas, 1994). That is to say, the therapy begins only when the therapist "enters" the world of the person-in-therapy.

During an existential therapeutic encounter, based on the various given information of the person-in-therapy, the therapist tries to construct the picture and life of this person-intherapy, for example, the person-in-therapy's relationship with themselves and others. The aim of existential therapy is eventually to inspire the person-in-therapy's positive decision and actual action. While psychotherapy is provided, so are the person-in-therapy's resolution and future possibilities. The task of the existential therapist is to assist the person-in-therapy 
to recover his or her ability of self-actualisation so as to activate other possibilities or projects in life. Hence, the therapeutic encounter in existential psychotherapy is a state when the person-in-therapy exposes and describes his or her turmoil and concerns to the therapist. Being an existential therapist means "The patient's will is first exercised in the therapeutic area where it is accepted and reinforced by the therapist” (Yalom, 1980, p. 339). This is a person-to-person encounter. The authentic presence of the therapist and the reciprocal interaction between the therapist and the person-in-therapy in the therapeutic encounter is the key to a successful therapeutic session. The therapeutic relationship between the therapist and the person-in-therapy determines whether a therapy session is effective or not. The value of the therapeutic relationship is that "the therapist develops a caring relationship that inspire freedom, openness, honesty, disclosure, and eventually trust and love... the therapist creates an atmosphere and a human presence that invite self-disclosure and facilitates understanding of the person-in-therapy” (Moustakas, 1994, p. 45). The therapist may impose his or her value judgment on the person-in-therapy during the therapeutic encounter in order to alleviate the person-in-therapy's neurosis. The same may be said that the therapist-patient relationship and therapeutic encounter help the person-in-therapy to confront the existential isolation. The representation of the therapist-patient relationship and therapeutic encounter in existential psychotherapy is not impersonal or disengaged. The existential therapist tries to understand the world of the person-in-therapy by empathy and listening. What are required in the existential psychotherapy situation are authentic being, and a genuine and trusting relationship shared by the therapist and the person-in-therapy.

\section{The Psychoanalytic Encounter in The Schopenhauer Cure}

After the theoretical discussion of Irvin Yalom's concepts of existential psychotherapy, my focus will shift to the crucial issue of the therapeutic encounter and therapist-patient relationship in his novel, The Schopenhauer Cure. Prior to The Schopenhauer Cure, Yalom published three other novels that explored existential and psychotherapeutic issues in a fictional framework. Although with a strong emphasis on philosophy, literature and psychotherapy, Yalom is not a theory-conscious writer as he states that "I would entirely jettison professional prose and jargon and teach through literature using the techniques of fiction to illuminate the inner world of both the client and the therapist” (Yalom, 2006, p.10). If we look at the aspect of how fictional characters' minds are constructed through fictional narrative, Yalom's conventional narrative in The Schopenhauer Cure has the traditional structure of a chronological order, in which there is a clear beginning, development and ending to the story. Beginning with Julius's diagnosis of melanoma, the narrative follows the progress of his supervised group therapy and ends with his death and its influence on his analysands. What is more, the omniscient narrator holds access to the information of the fictional characters' minds and with the disclosure of the plot, the features of the characters are gradually unfolded within the narrative developments. This narrative structure highlights how fiction can allow the reader to engage imaginatively with the lives and inner worlds of fictional characters. In The Schopenhauer Cure, with the concerns of how philosophical ideas, especially the reinterpretation of Schopenhauer's philosophy, may actually have a positive influence on psychotherapy, Yalom uses double story lines to compose two interwoven fictional worlds. One is that of the psycho-biographical narrative of 
Schopenhauer's life, which serves as the cross-reference to Philip's psychological development, the other is Julius and the individuals in group therapy. In both cases, the traditional narrative rules of exposition, climax and resolution are well-presented in The Schopenhauer Cure. It centralises the theme of the philosophical concerns of life meaning and how existential psychotherapy brings out the possibilities of cure in various therapistpatient relationships. It explores the multiple dimensions of the therapist-patient relationship in the psychoanalytic encounter of group therapy. For being in group therapy means one has to do one's best to explore one's relationship with everyone in the group. The therapist also has to undergo his own soul-searching work in the process. The strong contrast between Julius and Philip illuminates the resistant relationship of the analyst and the analysand. Moreover, the process of eliminating Philip's hostility and aloofness also demonstrates the major task of an existential psychotherapist: to build up an authentic relationship with the person-in-therapy in the psychoanalytic encounter. Hence, through Julius and Philip's therapist-patient relationship, The Schopenhauer Cure stresses that a successful existential psychoanalytic encounter occurs when the therapist is able to identify the person-in-therapy's existential vacuum and assist him or her to develop or discover his or her authentic purpose in life.

With the upcoming death of the psychotherapist, Julius, The Schopenhauer Cure focuses on the confrontation of death anxiety and existential isolation. Apart from showing dissatisfaction with the media's misrepresentation of group therapy, Yalom attributes his inspiration for writing The Schopenhauer Cure to the belief that "professional prose did not permit to convey what was truly the critical part of the therapy experience - the deep, intimate, human, risky, caring (even loving) texture of the therapist-client relationship” (Yalom, 2005, p. 10). In his fictional writings, Yalom tries to capture the essence of the therapist-patient relationship and the very humanistic side of such an encounter. Yalom considers his fictional writing as the medium to convey the nature and reality of existential psychotherapy. In the context of The Schopenhauer Cure, he centralises the psychoanalytic encounter in group therapy.

With an equal emphasis on both therapist and person-in-therapy's narratives, The Schopenhauer Cure presents the psychoanalytic encounter from both the therapist and the person-in-therapy's perspective. The premise of existential psychotherapy emphasies the four existential concerns, namely death, freedom, isolation and meaninglessness, and their impact often cause the person-in-therapy's strong existential anxiety, and as a result leads to psychoneuroses and subsequent psychotherapy. Yalom also takes the plunge and starts to write a serial of literary-therapy novels. In “A conversation with Irvin D. Yalom,” Yalom addresses his motive for fictional writing: "My stimulation as a writer is mental, from reading philosophy and fiction, and from my clinical work-hardly an hour of therapy with a patient goes by without some ideas being generated that will find their way into my writing” (6). Judging from the above, one may understand the combination of psychotherapy, philosophy and literature in Yalom's When Nietzsche Wept and The Schopenhauer Cure. As Yalom suggests in "Writing The Schopenhauer Cure," he considers that "Group therapy, based on interpersonal theory, makes the assumption that individuals fall into despair because they are unable to establish enduring, meaningful, sustaining relationships with others. Hence, the therapy is directed toward exploring what goes awry in the patient's attempt to make contact 
with others" (8). With this assumption in mind, the reader can not expect this novel to be merely the psychotherapist's monologue. It is, after all, a novel about relationships. Apart from the therapist-patient relationship, there are relationships among those who join group therapy and their respective relationships with others outside the group, as well as the referring relationship between Arthur Schopenhauer and one of the characters, Philip.

What makes the setting of group therapy so important is that members in this particular psychotherapy group will transfer or copy what they have gained from interrelation among members in the group to their real-life situation. The therapeutic encounter in The Schopenhauer Cure is a kind of "social microcosm” as Yalom called it (Yalom, 2005, p. 9). The focus of the here-and-now and interpersonal therapist-patient relationship, as well as the therapist's being with the person-in-therapy in therapeutic encounter are but three of the most distinctive characteristics of existential psychotherapy. The Schopenhauer Cure presents a psychoanalytic encounter with focalisation on the person-in-therapy's interpersonal issues and how they are examined in the group therapy session. It renders the reader able to reflect the psychoanalytic relationship from different perspectives.

Next, another way to look at the therapist-patient relationship in The Schopenhauer Cure is to examine the major story line of the therapist-patient relationship between Julius and Philip. Apart from the former three-year therapist-patient relationship, in return for the favour of Philip's participation in group therapy, Julius agrees to be a six-month consultancy supervisor of the philosophical-therapist-to-be Philip. Julius and Philip now also share a quasiapprenticeship. As a matter of fact, this agreement is Julius's last attempt to explore his previous failed psychoanalytic relationship with this specific former person-in-therapy, Philip. Nevertheless, what makes it almost an impossible task is Philip's untouchbility and social isolation, which has already made him a man who is unable to build up any authentic relationship with others. So this draws our attention to the essence of Julius and Philip's relationship: a tense therapist-patient relationship with strong resistance from the analysand. How does the person-in-therapy resist the analyst in psychotherapy? Is such resistance taken well by the analyst? Or must the person-in-therapy work with the therapist cooperatively? From the analyst's perspective, in Julius's psychoanalytic relationship with Philip, the strong resistance from Philip inspires Julius's own reflection about the therapist's function and role: "As I survived my life, I realized that I had experienced meaning - and that it always involved stepping outside of myself, helping others to live and to fulfill themselves” (267). Julius takes Philip not only as an example to reexamines his own clinical credentials but also as a person who still needs his professional assistance, “Where had Philip’s face, name, story been lurking all these years? He got to get his mind around the fact that the memory of his whole experience with Philip was contained neurochemically somewhere in the cortex of his brain” (23). In contrast to Julius's interpersonal relationship with other analysands, Philip, who cannot answer the question of "who is the real you?" yet considers himself as the modern incarnation of Schopenhauer, is the antagonist in the situation. Nevertheless, Philip's self-imposed aloofness does not give him the credit of freeing him from the existential situation, "Perhaps there's no hope for me. My slate of relationships, past and present, is blank. Not with family, not with friends, not with lovers. I treasure my solitude, but the extent of it would, I think, be shocking to you" (334). He has to confront his aloof relationship with others because with the ambition to become a philosophical therapist, Philip 
needs to confront his existential dilemma before he can actually help others. Under his isolation and untouchbility, Philip also reserves doubt about himself: "Philip felt jittery, uncomfortable in his skin. He sensed that he was in danger of unraveling....His former debased self was hovering like a ghost. He sensed its presence, thirsting for life” (276). How Julius and other analysands in the therapy group gradually shake off Philip's icy façade and get him to talk, and the authentic response is the highlight of the novel, as Philip confesses in group therapy that:

For the past twelve years I have been a visitor to life, an observer of the passing show and I have lived in tranquility. And now that this group has compelled me to once again be "in life," I am once again in anguish. I mentioned to you my agitation after that group meeting a few weeks ago. I have not regained my former equanimity. (318)

It is also worthwhile to examine the other ghost person-in-therapy in the novel, Arthur Schopenhauer. While The Schopenhauer Cure draws a parallel line between the fictional narrative of contemporary group therapy and the historical narrative of the psychobiography of Arthur Schopenhauer, such writing strategy stresses Phillip's contrast to Julius as well as his similarity to Schopenhauer. As Yalom explains, his inspiration for creating a character such as Philip was "What a challenge he would present for a group therapist! And what a kick it might be to have him in a group! And just think-if a group could help Arthur Schopenhauer, it could help anyone!" (13) ${ }^{\text {iv }}$. It leads to the discussion of the method of the cure in the novel. Since this novel focuses on the therapist-patient relationship in group therapy, what is the cure of group therapy? How does analyst Julius find the "cure" to his own inevitable death? How do other members in his group therapy find their respective cure, especially that of Philip? From the perspective of existential psychotherapy, Yalom proposes that the confrontation with death and being in this boundary situation often initiate one's inner awareness, dramatic personal change and rearrangement of life's priorities. As a result, the person-in-therapy might take this opportunity to transform their previous problematic life structure into the state of authentic being.

As far as Julius is concerned, with the belief of "consummate your life" and "Die at the right time," Julius tries to do something about his last days in life, "He knew exactly what to do and how to spend his final year. He would live just the way he had lived the previous yearand the year before that and before that. He loved being a therapist; he loved connecting to others and helping to bring something to life in them" (12). What is immediately apparent in this extract is that Julius tries to confront his death anxiety by purpose engagement and leading an authentic way of life.

Julius decides to do what he has been always good at - helping his patients. With Philip, Julius tries to teach him a lesson of how to become a therapist, as he tells Philip that "But, if you're to be a counselor, you must enter the social world. I want to remind you that many, I would bet most, of those who will consult you in your practice will need help in their interrelationships, and if you want to support yourself as a therapist, you must become an expert in these matters - there's no other way" (333). As for other patients, with the development of the story, one notices that Julius applies many approaches such as empathy, presence, genuine listening, and non-judgmental acceptance to encourage his patients to 
explore their relationship with others as much as possible. For being in group therapy means one has to do one's best to explore one's relationship with everyone in the group:

Just look around the group: everyone here entered because of conflicted relationships. Pam came in because of problems with the man in her life, Rebecca because of the way her looks influenced her relations with others, Tony because of a mutually destructively relationship with Lizzy and his frequent fights with other men, and so on for everyone (333).

Everyone brings his or her own burden to the group, but the problem is how could they find a way out? To take Philip's transformation for example, Philip learns how to overcome his existential neurosis by studying Schopenhauer's philosophy and claims that it is his ultimate cure in life. Nevertheless, by following Schopenhauer's philosophy, Philip also tries to imitate and lead an isolated life like Schopenhauer. As a result, he remains to be his one existential confinement. Tony, one of the patients in the group, has observed accurately, "I would say that Schopenhauer has cured you, but now you need to be saved from the Schopenhauer cure” (330). Philip does not need to imitate Schopenhauer or confine himself from relationships around him, but rather, he has to discover his own authentic engagement in life and explore his relationship with others in a new light. By the end of the novel, Philip transforms himself from the position of person-in-therapy to therapist. He symbolically takes the chair bequested by Julius and starts to work as a philosophical consultant. As a result, while Julius confronts his death anxiety, he also bequests his person-in-therapy an invaluable lesson: confronting one's existential anxiety by giving meaning to one's life. For Julius, he deals with his death anxiety by devoting the very last year of his life to his group therapy and trying to engage an authentic relationship with his patients. To conclude, Yalom takes the death of the therapist, Julius, as an example to explore the existential anxiety of this inevitable ending to everyone. While Julius faces the music, he also focuses his engagement, filling his life with meaning and authentic being. His effort and death evoke awareness in some of the group therapy members, and as a result, they undergo inner change and start to look at their own lives in a very different light. Being a group therapist, Julius is brave enough to reveal his issues in the presence of his analysands, "Before my melanoma I would never have said that I was in love with the group. I would never have dreamed of revealing such intimate details of my life-Miriam's death, my sexual opportunism. And my irresistible compulsion to confess to the group today" (252). In the context of existential psychotherapy, the most valuable tool possessed by a therapist is his own personality and engagement towards the person-in-therapy's situation. “Therapists care about their professional mission; the growth of other human beings matters to them; they help others, often in creative ways, to search for meaning” (Yalom, 1980, p. 483); before the analyst can initiate the person-in-therapy's engagement with his or her issues and handle relationships with others, the analyst has to relate to the analyst authentically in a psychoanalytic encounter.

To conclude, according to Yalom, engagement is the major therapeutic answer to meaninglessness and the person-in-therapy needs to be consistently reminded by that. One's desire to engage life is invaluable; apart from finding what is getting in the way of the person-in-therapy's life, it is also the therapist's task to help the person-in-therapy to do soulsearching and discover that particular engagement and "a good therapist's aim is to enable patients to leave therapy” (Yalom, 1980, p. 309). This may explain why Yalom leaves the 
ending of The Schopenhauer Cure at the moment of Philip and Tony's emergence as budding philosophical consultant and co-consultant in their first philosophical consultation group session. With the combination of existential psychotherapy, philosophy and fiction, Yalom not only suggests that one can take a profound lesson from philosophy, so as to confront inevitable existential anxiety and turn it into awakening experience, but also demonstrates this point in almost all of his non-fiction and fictional works. This leads to a different representation of a psychoanalytic encounter in The Schopenhauer Cure.

\footnotetext{
i According to Rollo May “...every scientific method rests upon philosophical presuppositions.” (46)

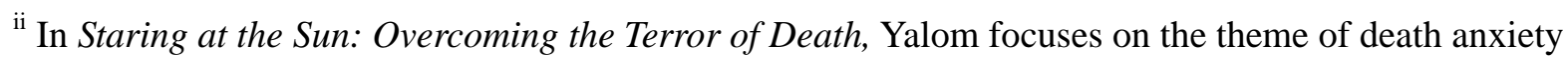
and how his patients deal with such inevitable anxiety in different stage of life.

${ }^{\text {iii }}$ In Escape from Freedom Fromm further explores the subject of freedom and treats the subject throughout from cultural and social perspectives.

${ }^{\text {iv }}$ Another quotation of Yalom is from North American Journal of Psychology: "Ultimately I created a character, Phillip, who was kind of a Schopenhauer clone, with the personality traits and world view to make him exactly like Schopenhauer. So, indirectly, I was having Schopenhauer treated in a therapy group.”
}

\section{Works cited:}

Davis, T. "The Relevance of the Freudian Concept of 'Transference' to Existential Psychotherapy.” Existential Analysis 18.2 (2007): pp. 348-57.

Evans, D. 1996. An Introductory Dictionary of Lacanian Psychoanalysis. London: Routledge. Freud, S. 1940. "An Outline of Psychoanalysis.” Historical And Expository Works on Psychoanalysis. Vol. 15. London: Penguin Books.

Furst, L. R. 1999. Just Talk: Narratives of Psychotherapy. Kentucky: The University Press of Kentucky.

Gerhardt, J., Sweetnam, A. “The Intersubjective Turn in Psychoanalysis,” Psychoanalytic Dialogues. 2001. 11(1): pp. 43-92.

Hamman, J. J. “The Search to Be Real: Why Psychotherapists Become Therapists,” Journal of Religion and Health 40. 3 (2001): pp. 343-57.

Keshen, A. “A New Look at Existential Psychotherapy,” American Journal of Psychotherapy 60:3 (2006): pp. 285-98.

Martz, E. "Principles of Eastern Philosophies Viewed from the Framework of Yalom's Four Existential Concerns.” International Journal for the Advancement of Counseling 24 (2002): pp. 3142.

May, R. 1994. The Discovery of Being. New York: Norton.

May, R. - Schneider, K. J., 1995. The Psychology of Existence. New York: McGraw-Hill.

Moustakas, C. 1994. Existential Psychotherapy and the Interpretation of Dreams. New York: Jason Aronson.

Szasz, T. “What is Existential Therapy Not?” Existential Analysis 16.1: (2005): pp.127-130.

Yalom, Irvin. 1974. Every Day Gets a Little Closer. New York: Basic Books.

---. 1980. Existential Psychotherapy. New York: Basic Books,.

---. 1989. Love's Executioner and Other Tales of Psychotherapy. New York: Harper Perennial.

---. 1992. When Nietzsche Wept. New York: Harper Perennial.

---. 1997. Lying on the Couch. New York: Harper Perennial.

---. 2000. Momma and the Meaning of Life. New York: Harper Perennial.

---. 2006. The Schopenhauer Cure. New York: Harper Perennial. 
---. 2008. Staring at the Sun: Overcoming the Terror of Death. New York: Jossey-Bass.

---. 2011. I'm Calling the Police. New York: Basic Books.

Huang, Yen-Chi

Faculty of Arts

Katholieke Universiteit Leuven

Belgium

yenchi.huang@student.kuleuven.be 